\title{
Inhibition of oxygen scavengers realized by peritoneal macrophages: an adhesion prevention target?
}

This article was published in the following Dove Press journal:

International Journal of Nanomedicine

14 November 2014

Number of times this article has been viewed

\section{Ospan A Mynbaev ${ }^{1-4}$ \\ Marina Yu Eliseeva ${ }^{1,2}$ \\ Oktay T Kadayifci ${ }^{1,5}$ \\ Tahar Benhidjeb 1,6 \\ Michael Stark ${ }^{1,4}$}

'The International Translational Medicine and Biomodeling Research team, MIPT Center for Human Physiology Studies, Laboratory of Cellular and Molecular

Technologies, The Department of Applied Mathematics, Moscow Institute of Physics and Technology (State University), Moscow Region, Russia; ${ }^{2}$ The Department of Obstetrics, Gynecology and Reproductive Medicine, Peoples' Friendship University of Russia, Moscow, Russia; ${ }^{3}$ Laboratory of Pilot Projects, Moscow State University of Medicine and Dentistry, Moscow, Russia; ${ }^{4}$ The New European Surgical Academy, Berlin, Germany; ${ }^{5}$ Onkim Stem Cell Technologies Inc., Istanbul, Turkey; ${ }^{6}$ Department of Surgery, Burjeel Hospital, Abu Dhabi, United Arab Emirates
Correspondence: Ospan A Mynbaev 9 Institutskiy per., Dolgoprudny, Moscow Region, 141700, Russian Federation Tel +74997926927

Email ospanmynbaev@hotmail.com

\section{Dear editor}

Our team, general surgeons and gynecologists look constantly for ways to prevent postsurgical adhesions, and hence, we appreciate the platform you have established through multiple publications. ${ }^{1-3}$ This is especially because postsurgical adhesions may result in several complications such as the small bowel obstruction, secondary infertility, dyspareunia, chronic abdominal/pelvic pain and many others.

Prevention of postsurgical adhesions is still an unsolved problem in spite of the suggested modifications of current surgical methods and application of various barriers, sprays, and use of other antiadhesive medications. We have already pointed out that a design of ideal nanoparticles should become a target of personalized adhesion prevention strategy in the future ${ }^{4,5}$ and therefore, we read with great interest the article by Shin et al that was recently published in your journal. ${ }^{6}$ This article explores the potential of postoperative adhesion prevention by nanofibers of poly(lactic-co-glycolic acid) (PLGA) loaded with epigallocatechin-3-O-gallate (EGCG), which is the most bioactive polyphenolic compound extracted from green tea.

The authors demonstrated that the effects of PLGA barrier loaded with EGCG in the prevention of adhesion are associated with the expression of its active compound. EGCG possesses an antioxidant activity as well as a prolonged activated partial thromboplastin time (aPTT) as reported by in vitro experiments. ${ }^{6}$ The authors also demonstrated the significantly inhibited inflammation, neovascularization and fibrosis in animals treated with PLGA barrier loaded with EGCG compared with PLGA treatment only. In addition, the use of EGCG was associated with significantly reduced severity and extent of posttraumatic adhesions when compared with that of Interceed TC7. ${ }^{6}$

As we reported before, an increased severity of adhesion was associated with accelerated activation of spontaneous chemiluminescence (SCL) of peritoneal macrophages (Figure 1). Two different adhesion barriers, TC7 with the size $0.3 \times 3.5 \mathrm{~cm}$ (Ethicon Company, Johnson \& Johnson) and Fibrin Glue (Beriplast, Behring, Germany), applied on suture lines made during experimental surgery in an incised rat uterine horn were compared with similar lesions sutured using catgut $4 / 0$ or prolene 4/0 (Ethicon Company, Johnson \& Johnson) without application of barriers. ${ }^{7,8}$ Peritoneal fluid was collected from the abdominal cavity of euthanized animals, and SCL patterns of freshly isolated macrophages were measured every day in three rats from each group. Changes in SCL were recorded and analyzed in comparison with the 
A

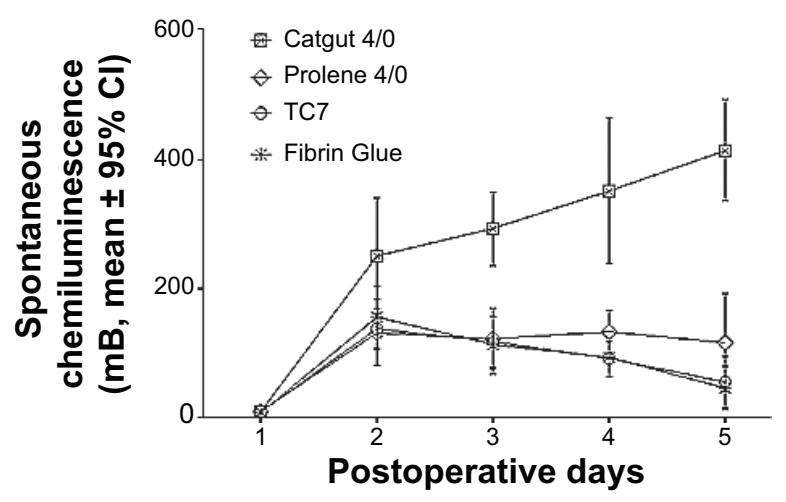

B

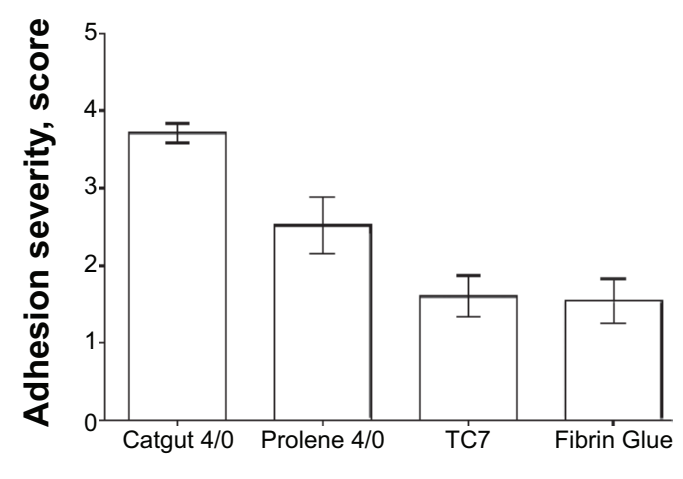

Figure I Postsurgical spontaneous chemiluminescence activity of freshly isolated peritoneal macrophages (A) and adhesion severity (B) after application of two different adhesion barriers, TC7 with the size $0.3 \times 3.5 \mathrm{~cm}$ (Ethicon Company, Johnson \& Johnson) and Fibrin Glue (Beriplast, Behring, Germany), on suture lines made during experimental surgery in an incised rat uterine horn were compared with similar lesions sutured using catgut 4/0 or prolene 4/0 (Ethicon Company, Johnson \& Johnson) without application of barriers.

Abbreviation: $\mathrm{Cl}$, confidence interval.

dynamic macroscopic and histological features of postsurgical acute inflammation, wound healing, and adhesion formation, which were observed under the transmission electron microscopy. Experiments were done with the approval of the Institutional Local Ethical committee (Academician V.I. Kulakov Research Center of Obstetrics, Gynecology, and Perinatology, Ministry of Health of Russia). ${ }^{7}$

In addition, we also found that there were reduced inflammation, neovascularization, and mild sclerotic changes after the application of both barriers ${ }^{7}$ as shown by Shin et al. ${ }^{6}$ Further studies evaluating the ability of EGCG to scavenge reactive oxygen species in peritoneal macrophages and cause prolonged activation of partial thromboplastin time in peritoneal fluid will enhance our current understanding of the related adhesion formation signaling pathways.

\section{Acknowledgments}

This work was supported by the Russian Science Foundation (grant no 14-31-00024).

\section{Author contributions}

All authors contributed toward data analysis, drafting and revising the paper and agree to be accountable for all aspects of the work.

International Journal of Nanomedicine

\section{Publish your work in this journal}

The International Journal of Nanomedicine is an international, peerreviewed journal focusing on the application of nanotechnology in diagnostics, therapeutics, and drug delivery systems throughout the biomedical field. This journal is indexed on PubMed Central, MedLine, CAS, SciSearch $®$, Current Contents $₫ /$ Clinical Medicine,

\section{Disclosure}

The authors have no conflicts of interest or financial ties to disclose. The authors alone are responsible for the content and writing of the paper.

\section{References}

1. Yang B, Gong C, Zhao X, et al. Preventing postoperative abdominal adhesions in a rat model with PEG-PCL-PEG hydrogel. Int $J$ Nanomedicine. 2012;7:547-557.

2. Gao X, Deng X, Wei X, et al. Novel thermosensitive hydrogel for preventing formation of abdominal adhesions. Int J Nanomedicine. 2013;8: 2453-2463.

3. Wu Q, Li L, Wang N, et al. Biodegradable and thermosensitive micelles inhibit ischemia-induced postoperative peritoneal adhesion. Int $J$ Nanomedicine. 2014;9:727-734.

4. Mynbaev OA, Eliseeva MY, Malvasi A, Tinelli A. Challenging nanoparticles: a target of personalized adhesion prevention strategy. Int $J$ Nanomedicine. 2014;9:3375-3376.

5. Mynbaev OA, Eliseeva MY, Tinelli A, et al. A personalized adhesion prevention strategy: Arslan E, Talih T, Oz B, Halaclar B, Caglayan K, Sipahi M. Comparison of lovastatin and hyaluronic acid/ carboxymethyl cellulose on experimental created peritoneal adhesion model in rats. Int J Surg. 12 (2) (2014) 120-124. Int J Surg. 2014;12(9): 901-905.

6. Shin YC, Yang WJ, Lee JH, et al. PLGA nanofiber membranes loaded with epigallocatechin-3-O-gallate are beneficial to prevention of postsurgical adhesions. Int J Nanomedicine. 2014;9:4067-4078.

7. Mynbaev OA. Etiology, pathogenesis and prevention principles of postoperative adhesions: $\mathrm{ScD}$ thesis. Moscow, 1997;45. Russian.

8. Myinbayev OA, Rubliova KI. Use of chemiluminescent method for evaluation of postoperative adhesion formation after reproductive pelvic surgery: an experimental study. Am J Reprod Immunol. 1996;36(4): $238-241$

\section{Dovepress}

Journal Citation Reports/Science Edition, EMBase, Scopus and the Elsevier Bibliographic databases. The manuscript management system is completely online and includes a very quick and fair peer-review system, which is all easy to use. Visit http://www.dovepress.com/ testimonials.php to read real quotes from published authors. 